|Araştırma Makalesi / Research Article|

\title{
Öğrencilerin Artırılmış Gerçeklik Uygulamaları Üzerine Görüşleri: Optik Ünitesi Örneği
}

\section{Students' Views on Augmented Reality Applications: Optical Unite Example}

\section{Mehmet Karakaş ${ }^{1}$, Mehmet Arif Özerbaş ${ }^{2}$}

Anahtar Kelimeler

Artırılmış gerçeklik

Fizik eğitimi

Optik Ünitesi

Öğrenci Görüşleri

\section{Keywords}

Augmented reality

Physics education

Optical unit

Students views

Başvuru Tarihi/Received

25.01.2020

Kabul Tarihi /Accepted

21.07.2020

\section{Öz}

Bu araştırmanın amacı öğrencilerin artırımış gerçeklik uygulamaları üzerine görüşlerini belirlemektir. Araştırmada nitel araştırma yöntemleri kullanılmıştır ve yarı yapılandııılmış görüşme formu aracılı̆̆ı ile öğrencilerin görüşleri alınmıştır. Araştırma Tokat ili Merkez ilçede bulunan Gaziosmanpaşa Lisesi'nde öğrenim gören 33 öğrenci üzerinde gerçekleştirilmiştir. Öğrenciler ile 8 haftalık deney süresinin sonunda görüşmeler gerçekleştirilmiştir. Öğrencilerin artırılmış gerçeklik uygulamalarına ilişkin görüşlerinin belirlenebilmesi için içerik analizi yöntemlerinden (betimsel) frekans analizi yapılmıştır. Elde edilen bulgular ışığında yorumlamaya gidilmiştir. Araştırma sonucunda artırılmış gerçeklik uygulamalarının kullanıldığı bir öğretim sürecinde öğrencilerin derslere daha ilgili ve istekli oldukları sonucuna ulaşılmışır. Öğrencilerin çoğunun artııımış gerçeklik ile ders çalışmayı güzel olarak nitelendirdikleri, daha eğlenceli bir ortamda öğrendikleri, konuları daha iyi öğrendiklerini ve anladıkları sonuçlarına ulaşıımıştır. Ayrıca araştırma kapsamında hazırlanan uygulamalar ve işaretleyiciler ile ilgili öğrencilerin çoğunun olumlu tutuma sahip oldukları sonucuna ulaşılmıştır. Öğrenciler en çok yazılımın yavaş çalışması ile ilgili sorunlar yaşadıklarını ve hazırlanan yazılımın daha hızlı olması gerektiğini belirtmişlerdir. Öğrenciler kullanılan donanımsal aygıtların daha güncel olması gerektiğini belirtmişlerdir.

\section{Abstract}

The aim of this research is to determine the students' views on augmented reality applications. Qualitative research methods were used in the study and opinions were obtained from students through semi-structured form. The study was carried out on 33 students studying in Gaziosmanpaşa High School in the central district of Tokat. At the end of the 8-week experiment period, the students were interviewed. In order to determine the students' views on augmented reality applications, frequency analysis was conducted through content analysis methods (descriptive). Interpretation was made in the light of the findings. As a result of the research, it is concluded that students are more interested and willing to the lessons in a teaching process where augmented reality applications are used. It was concluded that most of the students described the study with augmented reality as good, learned in a more fun environment, learned the subjects better and understood. In addition, it was concluded that most of the students had positive attitudes regarding the applications and markers prepared within the scope of the research. Most of the students stated that they had problems with the slow running of the software and that the software should be faster. Students stated that the hardware devices used should be more up-to-date.

\footnotetext{
${ }^{1}$ Sorumlu Yazar, MEB, Tokat Cumhuriyet Mesleki ve Teknik Anadolu Lisesi, Tokat, Türkiye; https://orcid.org/0000-0002-1127-1135 


\section{Extended Abstract}

\section{Introduction}

The aim of this study is to determine the students' views on the augmented reality applications which are developed. In this context, the following questions were sought.

What are the students' views on augmented reality applications?

What are the difficulties students face with augmented reality applications?

What elements of augmented reality have students enjoyed?

What contribution did augmented reality applications have to students?

What elements of augmented reality should be added according to the students' views?

\section{Method}

The research was conducted in a qualitative design. At the end of an experimental study, the opinions of the students were obtained in the experimental group about the independent variable in the experimental process

In the research, the teaching of the optical unit of physics lesson to the group of students with experimental process was done with augmented reality applications. The application was completed in 16 hours for 8 weeks, 2 hours per week. As a result of the application, 33 students who were in the experimental group of the research were interviewed about the application.

Data were collected through a semi-structured interview form with the experimental group students participating in the application. The interview form was prepared by adapting regarding the student views about digital class previously prepared by Özerbaş and Erdoğan (2015). Each of the questions was prepared to obtain different data. Data were entered into Spss program by the researcher. In order to determine the students' views on augmented reality applications, frequency analysis was conducted through content analysis methods (descriptive).Interpretation was made in the light of the findings.

\section{Result and Discussion}

When the answers of the students to the first question in order to determine the views of the students about the augmented reality applications were examined, it was concluded that the students had very positive thoughts about the augmented reality applications. This finding shows that students may be more interested and willing to the lessons in a teaching process with using augmented reality applications.

Within the scope of the research, When the answers of the students to the "What are the challenges you face when using augmented reality applications? " question were examined, it was concluded that the students experienced the problems related to the slow operation of the software. Apart from this, it is seen that the students do not encounter any great difficulties regarding augmented reality applications.

Within the scope of the research, When the answers of the students to the "What did you like when trying augmented reality applications?" question were examined, it was concluded that most of the students described the study with augmented reality as beautiful and that the students learned in a more fun environment. It can be said that most of the students are particularly positive about the applications and markers prepared within the scope of the research.

Within the scope of the research, When the answers of the students to the "What did augmented reality applications contribute to you?" question were examined, students stated that augmented reality has many contributions. They stated that they learned and understood the subjects better especially with augmented reality applications.

Within the scope of the research, When the answers of the students to the "What would you like to add again if you wanted to learn the subjects in an environment prepared with augmented reality applications? " question were examined, they stated that the hardware devices used should be higher level and the software prepared should be faster The majority of the students in the experimental group, where augmented reality applications were shown, stated that the lessons were more enjoyable and tasteful.With this aspect, it can be said that the teaching process has become more enjoyable with augmented reality applications. The students stated that they learned the subjects better with augmented reality applications. For this reason, it is thought that it will be beneficial to use augmented reality-based applications more in the teaching process since it attracts attention of students and has a positive effect on their learning. Most of the students described the marker based augmented reality applications about physics lesson optical unit as fun, beautiful and educational. Therefore, with marker-based augmented reality applications, the teaching process can be designed in a more fun, beautiful and educational way.

The students stated that the phones they used within the application should be newer and faster. It may be assumed that the students assume that the new technological tools will provide convenience when trying the prepared applications. In addition, it was stated by the students that besides the smartphones and tablets, the applications could be tried via desktop computer and web cam. However, special environments can be designed for future augmented reality applications and the applications can be realized more effectively.

In terms of software, very few students reported problems with the slow running of applications, and other than that, students did not encounter any major difficulties with augmented reality applications. The speed problem with the software may be due to the fact that some students have older phones. For this reason, technological tools with ready-made tablets or computer systems can be offered to students in future applications.

They also think that there should be more activities than the ones shown. Therefore, many augmented reality applications can be developed and tested on different topics in different subjects. 
Students' desire to work more with augmented reality applications, having more interaction in applications and having questions in applications are among the important opinions of the students. In this context, these issues can be taken into consideration for future applications. Students stated that augmented reality applications can be used in other courses as well.

\section{GiRiş}

Günümüzde teknoloji hızla gelişmekte ve eğitim sistemleri de bu değişimden etkilenmektedir. Özellikle bilgisayar teknolojisinin eğitim teknolojileri açısından geçmişten bugüne önemli bir yeri olmuş ve etkin bir biçimde bilgi toplumu sürecinde kullanılmıştır (İşman, 2001). Son yıllarda ise Endüstri 4.0 yani 4. Sanayi devriminden bahsedilmekte ve üretim sisteminin değişeceği bununla beraber yeni teknolojilerin etkin olarak kullanılacağı varsayılmaktadır. Öztemel (2018) endüstri 4.0 ile gelişen teknolojilerin sadece üretimsel alanlarda değil aynı zamanda eğitim sistemlerinde de etkili olacağını belirtmektedir. Fisk (2017) gelecekteki öğrenmenin tamamen farklı olacağını belirtmekte ayrıca Endüstri 4.0’ün gereksinimlerine cevap veren, kişiselleştirilmiş veriyi, açık kaynaklı içeriği, dijital teknolojilerin potansiyelinden faydalanma gibi birçok özelliğinin olacağını belirtmektedir.

Endüstri 4.0'ün temel bileşenlerinden biri olan artırılmış gerçeklik son yıllarda popüler olan bir kavramdır. Azuma (1997) artırılmış gerçekliği gerçek dünya ile sanal nesnelerin birleştiği, gerçek ve sanal nesneler arasında eş zamanlı bir etkileşimin sağlandığı teknoloji olarak tanımlamaktadır. Artırılmış gerçekliğin gerçek ve sanal dünyayı birleştirmesi, gerçek zamanlı etkileşimli ve üç boyutlu olması gibi üç önemli özelliği bulunmaktadır (Azuma,1997; Krevelen ve Poelman, 2010; Lopez, Perez ve Contero, 2013; Wu, Lee, Chang ve Liang, 2013, Alkhamisi ve Monowar, 2013; Nielsen, Brandt ve Swensen, 2016).

Artırımış gerçeklik günümüzde tıp, mühendislik, üretim, onarım, reklam, askeriye, eğitim, eğlence, tasarım, görselleştirme gibi birçok alanda kullanılmaktadır (Yen, Tsai ve Wu, 2013; Azuma, 1997; Alkhamisi ve Monowar, 2013; Siltanen, 2012; Lee, 2012). Eğitsel açıdan literatür incelendiğinde artırılmış gerçeklik ile ilgili matematik (Coimbra, Cardoso ve Mateus, 2015; Akkuş ve Özhan, 2017; Gün ve Atasoy, 2017), geometri (ibili, 2013), kimya (Singhal, Bagga, Goyal ve Saxena, 2012), fen (Kerawall, Luckin, Seljeflot ve Woolard, 2006; Fleck ve Simon, 2013; Yen, Tsai ve Wu, 2013; Cheng ve Tsai, 2013; Fleck, Hachet ve Bastien, 2015; Swensen, 2016; Kırıkkaya ve Şentürk, 2018;), tıp (Torregrosa, Torralba, Jimenez, Garcia ve Barcia, 2014; Küçük, 2015), yabancı dil (Akçayır, 2016; Hsu, 2017), sanat (Serio, Ibanez ve Kloos, 2013), fizik (Dünser, Walker, Horner, Bentall, 2012 ; Abdüsselam, 2013; Özarslan, 2013; Kuhn ve diğ, 2015) gibi birçok alanda çalışma yapılmıştır. Bütün bu çalışmalar artırılmış gerçeklik uygulamalarının eğitsel açıdan gelecekte birçok farklı disiplinde uygulanabileceğini ve geliştirilebileceğini göstermektedir.

Artırımış gerçeklik teknolojisinin uygulandığı önemli bir alan ise eğitim alanıdır. Eğitsel açıdan birçok alanda artırılmış gerçeklik uygulamaları geliştirilmekte ve denenmektedir. Artırılmış gerçeklik teknolojisinin eğitimde kullanılması ile birlikte birçok eğitsel faydadan bahsedilmekte ve bazı değişkenler açısından etkili olduğu belirtilmektedir. Akçayır ve Akçayır (2017) artırılmış gerçeklik uygulamalarının öğrenmeyi daha eğlenceli bir hale getirdiğini ve öğrencilerin daha iyi anladıklarını, Sırakaya ve Seferoğlu (2016) aynı şekilde artırılmış gerçeklik uygulamalarının öğrenmeyi daha eğlenceli hale getirdiğini belirtmektedir. Rambli, Matcha ve Sulaiman (2013) artııımış gerçeklik uygulamalarının öğrenme sürecinde katılımı artırdığı ve eğlenmeyi sağladığını belirtmektedir. Abdüsselam (2014) artııımış gerçeklik ortamının öğrencilerin olayları daha iyi anlamalarına ve kavramalarına yardımcı olduğunu ve bu ortamın uygulamalarda daha gerçekçi bir ortam sunduğu, görselleştirdiği ve kavramları somutlaştırdığını belirtmektedir. Küçük, Kapakin ve Göktaş (2015) artırılmış gerçeklik teknolojisinin öğrenme açısından gerçeklik hissi oluşturduğunu, konuyu somutlaştırdığını, derse karşı ilgiyi artırdığını belirtmiştir. Bu sebeple yeni bir teknoloji olan artırılmış gerçeklik teknolojisi üzerinde önemle durulması ve farklı dersler, konular veya disiplinler üzerinde uygulanmasının önemli olacağı düşünülmektedir.

Fizik bilimi ise uygulanabilecek alanların başında gelmektedir. Çünkü fizik bilimi birçok soyut kavramlar içermekte, görsel zekâ gerektirme ve öğrenciler bu kavramlar açısından zorlanmaktadırlar (Şengören, Tanel ve Kavcar, 2006; Cai, Chiang, Sun ve Lee, 2017). Yeni gelişen teknolojilerin ışığında fizik ile ilgili yeni öğretimsel stratejilerin, yöntem ve tekniklerin bu sebeple önemli olacağı düşünülmektedir. Nitekim artırılmış gerçeklik uygulamaları ile fizik eğitimi alanında birçok çalışma yapılmıştır (ibanez, Serio, Villaran ve Kloos, 2014; Abdüsselam, 2014; Techakosit ve Nilsook, 2015; Cai, Chiang, Sun ve Lee, 2017). Bu çalışmalara benzer çalışmaların yapılması ve öğrencilerin bu çalışmalara vereceği tepkiler bu sebeple önemlidir. Artırılmış gerçeklik teknolojisi günümüzde yaygın olmayan fakat gelecekte yaygın olması öngörülen teknolojilerden biridir. Bu nedenden dolayı da artırılmış gerçeklik uygulamaları üzerine yapılacak olan çalışmalar çoğalmalı ve öğretimin merkezinde yer alan öğrencilerin görüşleri incelenmelidir.

Türkiye'de fizik öğretiminde öğrencilerin artırılmış gerçeklik teknolojisi üzerine olan düşüncelerinin incelenmesi, öğrencilerin artırılmış gerçeklik teknolojisine verdikleri tepkinin ne olduğu, artırılmış gerçeklik ile bir dersin öğretiminin öğrencilerden tarafından nasıl değerlendirileceği gibi çeşitli problemler öne çıkmaktadır. Bu bağlamda öğrencilerin artırılmış gerçeklik teknolojisi üzerine düşüncelerini incelemek ve analiz etmek bu araştırmacının temel problemini oluşturmaktadır.

\section{YÖNTEM}

\section{Araştırma Modeli}

Araştırma nitel desende oluşturulmuş ve yürütülmüştür. Deneysel bir çalışma sonunda deney grubunda yer alan öğrencilerden deneysel işlemde bağımsız değişkene yönelik görüşler alınmıştır. Nitel araştırmada gözlem, görüşme, doküman analizi gibi nitel veri toplama yöntemleri ile algılar ve olayların doğal ortamda gerçekçi ve bütüncül bir biçimde ortaya konulması amaçlanmaktadır. 
Öğrencilerin AG uygulamalarına ilişkin görüşlerinin belirlenebilmesi için içerik analizi yöntemlerinden (betimsel) frekans analizi yapılmıştır (Yıldırım ve Şimşek, 2005). Elde edilen bulgular ışığında yorumlamaya gidilmiştir.

\section{Deneysel İşlem}

Uygulama kapsamında deneysel işlemin yapıldığı öğrenci grubuna fizik dersi optik ünitesinin öğretimi artırımış gerçeklik uygulamaları ile yapılmıştır. Uygulama haftada 2 saat olmak üzere 8 hafta boyunca 16 saatte tamamlanmıştır.

Uygulama öncesi çeşitli uzmanlardan görüş alınarak fizik dersi optik ünitesi üzerine artırımış gerçeklik uygulamaları geliştirilmiştir. Geliştirilen uygulamaların akıllı telefonlarda, tabletlerde ve kişisel bilgisayarda çalışabilmesi sağlanmıştır. Uygulamayı yapacak öğretmen için geliştirilen yazılım hem Windows ve hem de Android tabanlı geliştirilmiştir. Daha sonra geliştirilen yazııımın öğrencilerin kullanabilmesi için "Google Play" e yüklenmiştir. Öğrenciler akıllı telefonları aracılığı ile yazılımı kendi telefonlarına yükleyebilmişlerdir. Uygulama öncesi deney grubu öğrencilerine çalışma ile ilgili her türlü bilgi verilmiş ve artııılmış gerçeklik teknolojisi tanıtılmıştır. Uygulama süresince önce fizik dersi optik ünitesi ile ilgili teorik bilgi verilmiş daha sonra ise artırımış gerçeklik uygulaması gösterilip yapılmışır. Her hafta bütün öğrencilere hazırlanan işaretleyiciler (marker) dağıtılmış, öğrencilerin bu işaretleyicileri kullanarak uygulamaları denemeleri sağlanmıştır. Uygulama sırasında IOS tabanlı telefona sahip öğrenciler belirlenmiş ve onlar içinde teknolojik cihaz desteği sağlanmıştır. Öğrenciler uygulamaları bireysel veya grup içerisinde uygulamışlardır. Uygulama sonunda deney grubu öğrencileri ile yarı yapılandırılmış görüşme formu ile görüşme yapılmıştır.

\section{Çalışma Grubu}

Bu araştırma 2017- 2018 eğitim öğretim yılı içerisinde Tokat Merkez ilçesinde MEB'e bağlı bir lisede yapılmıştır. Araştırmanın çalışma grubu biri deney, biri kontrol grubu olmak üzere iki 10. sınıf oluşturmaktadır. Uygulama sonucunda araştırmanın deney grubunu oluşturan 33 öğrenci ile uygulamaya ilişkin görüşme yapılmıştır.

\section{Veri Toplama Araçları}

Uygulama sonucunda uygulamaya katılan deney grubu öğrencileri ile yarı yapılandırımış görüşme formu aracılı̆ıı ile veriler toplanmıştır. Görüşme formu daha önce Özerbaş ve Erdoğan (2015) tarafından hazırlanan "Dijital Sınıfa Iliş̧kin Öğrenci Görüşleri" formu uyarlanarak hazırlanmıştır. Soruların her biri farklı verileri elde etmek üzere hazırlanmışıı. Uygulama sonucunda araştırmanın deney grubunu oluşturan 33 öğrenci ile uygulamaya ilişkin görüşme yapılmıştır. Görüşme formunda yer alan ve öğrencilere yöneltilen sorular şu şekildedir:

1. Artırılmış gerçeklik uygulamalarına yönelik görüşleriniz nelerdir?

2. Artırılmış gerçeklik uygulamaları ile ilgili varsa karşılaştığınız güçlükler nelerdir?

3. Artırılmış gerçeklik uygulamalarını denerken nelerden hoşlandınız?

4. Artırılmış gerçeklik uygulamalarının size ne gibi katkıları oldu?

5. Tekrar artırııış gerçeklik uygulamaları ile hazırlanmış bir ortamda konuları öğrenmek isteseydiniz neler eklemek isterdiniz?

6. Uygulamaya yönelik eklemek istedikleriniz nelerdir?

\section{Verilerin Analizi}

$\mathrm{Bu}$ araştırmada veri toplama ve analizlerde nitel araştırma teknikleri toplanmıştır. Araştırmacı tarafından veriler bilgisayar ortamında Spss programına girilmiştir. Daha sonra içerik analizi yapılarak veriler çözümlenmiştir. Öğrencilerin görüşlerini ifade eden temaların frekans ve yüzdeleri belirlenmiştir. Elde edilen bulgular ışı̆ı̆ında yorumlamaya gidilmiştir

\section{BULGULAR}

\section{Öğrencilerin Artırılmış Gerçeklik Uygulamalarına Yönelik Görüşleri}

Deney grubu öğrencilerinin artııılmış gerçeklik uygulamalarına yönelik görüşlerini tespit etmek amacıyla yöneltilen birinci soru ve alınan yanıtlar Tablo 1'de belirtilmiş ve yorumlanmıştır.

\section{Tablo 1. Artırılmış Gerçeklik Uygulamalarına Yönelik Öğrenci Görüşleri}

\begin{tabular}{|c|c|c|c|}
\hline A. Artırılmış gerçeklik uygulamalarına yönelik görüşleriniz nelerdir? & $\mathrm{N}$ & $f$ & $\%$ \\
\hline Konuları daha iyi öğreniyorum. & 32 & 23 & 70 \\
\hline Artırılmış gerçeklik uygulamaları ile ders işlemek hoşuma gidiyor. & 33 & 26 & 79 \\
\hline Dersler daha zevkli ve eğlenceli oluyor. & 33 & 29 & 88 \\
\hline Artırılmış gerçeklik uygulamaları ile konuları tekrar etmek daha kolay oluyor. & 33 & 22 & 66 \\
\hline Konuları daha kolay öğreniyorum. & 32 & 22 & 66 \\
\hline
\end{tabular}

Deney grubu öğrencilerine yöneltilen “Artııımış gerçeklik uygulamalarına yönelik görüşleriniz nelerdir?” soru başlığı altındaki alt sorulara sırayla bakıldığında öğrencilerin \%70'i “Konuları daha iyi öğreniyorum.” yanıtını vermiştir. Bu seçeneğe verilen cevaplar 
incelendiğinde öğrencilerin büyük çoğunluğunun artırılmış gerçeklik teknolojisi ile konuları daha iyi öğrendiği söylenebilir. Öğrencilerin \%79’u “Artırılmış gerçeklik uygulamaları ile ders işlemek hoşuma gidiyor." yanıtını vermiştir. Bu seçeneğe verilen cevaplar incelendiğinde öğrencilerin büyük çoğunluğunun artırımış gerçeklik uygulamaları ile dersin işlenmesinden hoşlandığı söylenebilir. Öğrencilerin \%88'i "Dersler daha zevkli ve eğlenceli oluyor." yanıtını vermiştir. Bu seçeneğe verilen cevaplar incelendiğinde öğrencilerin büyük çoğunluğunun artırılmış gerçeklik uygulamalarını zevkli ve eğlenceli olarak algıladıkları söylenebilir. Bunun diğer bir nedeni olarak öğrencilerin artırılmış gerçeklik teknolojisini ilgi çekici olarak görmelerinden kaynaklanabilir. Öğrencilerin \%66’sı "Artırılmış gerçeklik uygulamaları ile konuları tekrar etmek daha kolay oluyor." yanıtını vermiştir. Bu seçeneğe verilen cevaplar incelendiğinde öğrencilerin konuları artırılmış gerçeklik uygulamaları ile tekrar etmelerinin daha kolay olduğu söylenebilir. Öğrencilerin $\% 66$ 'sı "Konuları daha kolay öğreniyorum." yanıtını vermiştir. Bu seçeneğe verilen cevaplar incelendiğinde öğrencilerin konuları artırılmış gerçeklik teknolojisi ile daha kolay öğrendikleri söylenebilir. Öğrencilere ön test ve son test olarak uygulanan akademik başarı testinin sonuçları bu görüş ile paraleldir.

Birinci alt probleme ilişkin bulgular incelendiğinde öğrencilerin artırılmış gerçeklik uygulamalarına yönelik oldukça olumlu düşüncelere sahip oldukları görülebilir. Bu bulgu öğrencilerin artırılmış gerçeklik uygulamalarının kullanıldığı bir öğretim sürecinde öğrencilerin derslere daha ilgili ve istekli olabileceğini gösterebilir.

\section{Öğrenciler artırılmış gerçeklik uygulamaları ile ilgili ne tür güçlüklerle karşılaşmaktadırlar?}

Deney grubu öğrencilerinin artırılmış gerçeklik uygulamalarına yönelik görüşlerini tespit etmek amacıyla yöneltilen ikinci soru ve alınan yanıtlar Tablo 2'de belirtilmiş ve yorumlanmıştır.

\section{Tablo 2. Artırılmış gerçeklik uygulamaları ile ilgili karşılaşılan güçlükler}

\begin{tabular}{|c|c|c|c|}
\hline B. Artırılmış gerçeklik uygulamaları ile ilgili varsa karşılaştığınız güçlükler nelerdir? & $\mathrm{N}$ & $f$ & $\%$ \\
\hline Yazılım çok yavaş çalışıyor & 33 & 2 & 6 \\
\hline Yazılım donuyor & 33 & 3 & 9 \\
\hline Hiç bir güçlük yaşamadım & 33 & 19 & 58 \\
\hline Yazılım çok yavaş olduğu için zorlandım & 33 & 3 & 9 \\
\hline Yazılım kendi kendine kapandığı için sorun yaşadım & 33 & 2 & 6 \\
\hline Yazılım kullanmayı bilmediğim için zorlandım & 33 & 1 & 3 \\
\hline
\end{tabular}

Artırılmış gerçeklik uygulamaları ile ilgili karşılaşılan güçlükleri tespit etmek amacıyla "Artırılmış gerçeklik uygulamaları ile ilgili varsa karşılaştığınız güçlükler nelerdir?" sorusu adı altında çeşitli alt sorulara yer verilmiş ve öğrencilerin cevapları alınmıştır. Öğrencilerin \%6'sı "Yazılım çok yavaş çalışıyor" yanıtını vermiştir. Öğrencilerin \%9'u "Yazılım donuyor" yanıtını vermiştir. Öğrencilerin \%58'i “Hiç bir güçlük yaşamadım" yanıtını vermiştir. Öğrencilerin \%9'u "Yazılım çok yavaş olduğu için zorlandım” yanıtını vermiştir. Öğrencilerin \%6”sı "Yazılım kendi kendine kapandığı için sorun yaşadım” yanıtını vermiştir. Öğrencilerin \%3'ü "Yazılım kullanmayı bilmediğim için zorlandım" yanıtını vermiştir. Bu soruya verilen cevaplar incelendiğinde öğrencilerin en çok yazılımın yavaş çalışması ile ilgili sorunlar yaşadığı söylenebilir. Bunun dışında öğrencilerin artırılmış gerçeklik uygulamaları ile ilgili büyük bir güçlükle karşılaşmadığı söylenebilir.

\section{Öğrenciler artırılmış gerçeklik uygulamaların denerken hangi faktörlerden hoşlanmışlardır.}

Deney grubu öğrencilerinin artırılmış gerçeklik uygulamalarını denerken hangi faktörlerden hoşlandıklarını tespit etmek amacıyla yöneltilen üçüncü soru ve alınan yanıtlar Tablo 3'te belirtilmiş ve yorumlanmıştır.

Tablo 3. Artırılmış gerçeklik uygulamalarını denerken nelerden hoşlandınız?

\begin{tabular}{|c|c|c|c|}
\hline C. Artırılmış gerçeklik uygulamalarını denerken nelerden hoşlandınız? & $\mathrm{N}$ & $f$ & $\%$ \\
\hline Artırılmış gerçeklik uygulamaları ile ders çalışmak çok güzel & 33 & 23 & 70 \\
\hline Konuları daha eğlenceli bir ortamda öğrendim & 33 & 25 & 76 \\
\hline Konu sonlarındaki markerlar çok güzel ve eğiticiydi & 33 & 26 & 80 \\
\hline Ders ile ilgili artırılmış gerçeklik uygulamalarını çok beğendim & 33 & 28 & 85 \\
\hline Markerlar çok eğlenceliydi & 33 & 25 & 76 \\
\hline Daha iyi fiziği öğrendim & 33 & 21 & 64 \\
\hline
\end{tabular}

Öğrencilerin artırılmış gerçeklik uygulamalarını denerken nelerden hoşlandığını tespit etmek amacıyla "Artırılmış gerçeklik uygulamalarını denerken nelerden hoşlandınız?" sorusu adı altında çeşitli alt sorulara yer verilmiş ve öğrencilerin cevapları alınmıştır. Öğrencilerin \%70’i “Artırılmış gerçeklik uygulamaları ile ders çalışmak çok güzel” yanıtını vermiştir. Öğrencilerin \%76'sı 
“Konuları daha eğlenceli bir ortamda öğrendim” yanıtını vermiştir. Öğrencilerin \%80'i “Konu sonlarındaki markerlar çok güzel ve eğiticiydi” yanıtını vermiştir. Öğrencilerin \%64'ü “Ders ile ilgili artırılmış gerçeklik uygulamalarını çok beğendim” yanıtını vermiştir. Öğrencilerin \%76'sı “Markerlar çok eğlenceliydi” yanıtını vermiştir. Öğrencilerin \%64'ü “Daha iyi fiziği öğrendim” yanıtını vermiştir. Bütün bu yanıtlar doğrultusunda öğrencilerin çoğunun artırılmış gerçeklik ile ders çalışmayı güzel olarak nitelendirdiği, öğrencilerin daha eğlenceli bir ortamda öğrendiği söylenebilir. Özellikle araştırma kapsamında hazırlanan uygulamalar ve markerlarla ilgili öğrencilerin çoğunun olumlu tutuma sahip olduğu söylenebilir.

\section{Artırıımış gerçeklik uygulamalarının öğrencilere katkıları nelerdir?}

Deney grubu öğrencilerinin artırılmış gerçeklik uygulamalarının katkılarını tespit etmek amacıyla yöneltilen ikinci soru ve alınan yanıtlar Tablo 4'te belirtilmiş ve yorumlanmıştır.

Tablo 4. Artırılmış gerçeklik uygulamalarının size ne gibi katkıları oldu?

\begin{tabular}{|c|c|c|c|}
\hline D.Artırılmış gerçeklik uygulamalarının size ne gibi katkıları oldu? & $\mathrm{N}$ & $f$ & $\%$ \\
\hline Konuları daha iyi öğrendiğimi düşünüyorum & 33 & 19 & 58 \\
\hline Optik ünitesini daha iyi anlamamı sağladı. & 33 & 24 & 73 \\
\hline Uygulamalar ile konuları daha çok tekrar etme fırsatım oldu. & 33 & 15 & 54 \\
\hline Fizik dersini daha çok sevmeye başladım. & 33 & 28 & 45 \\
\hline Hazırlanan yazılım ile konuları daha kolay öğrendim. & 33 & 19 & 57 \\
\hline Fizik dersinde başarımı artırdığını düşünüyorum. & 33 & 13 & 39 \\
\hline Akıllı telefonu veya tableti eğitsel amaçlı etkin bir biçimde kullanmayı geliştirdim & 32 & 24 & 72 \\
\hline Artırılmış gerçeklik uygulamaları ile öğrenmenin bana katkısı olduğunu düşünmüyorum & 33 & 7 & 7 \\
\hline
\end{tabular}

Artırımış gerçeklik uygulamalarının öğrencilere katkılarını tespit etmek amacıyla "Artırılmış gerçeklik uygulamalarının size ne gibi katkıları oldu?" sorusu adı altında çeşitli alt sorulara yer verilmiş ve öğrencilerin cevapları alınmıştır. Öğrencilerin \%58'i "Konuları daha iyi öğrendiğimi düşünüyorum" yanıtını vermiştir. Öğrencilerin \%73'ü "Optik ünitesini daha iyi anlamamı sağladı." yanıtını vermiştir. Öğrencilerin \%54'ü "Uygulamalar ile konuları daha çok tekrar etme fırsatım oldu." yanıtını vermiştir. Öğrencilerin \%45’i "Fizik dersini daha çok sevmeye başladım." yanıtını vermiştir. Öğrencilerin \%57'si "Hazırlanan yazııı ile konuları daha kolay öğrendim." yanıtını vermiştir. Öğrencilerin \%39'u "Fizik dersinde başarımı artırdığını düşünüyorum.” yanıtını vermiştir. Öğrencilerin \%72'si "Akıllı telefonu veya tableti eğitsel amaçlı etkin bir biçimde kullanmayı geliştirdim” yanıtını vermiştir. Öğrencilerin \%7'si “Artırılmış gerçeklik uygulamaları ile öğrenmenin bana katkısı olduğunu düşünmüyorum” yanıtını vermiştir. Verilen yanıtlar incelendiğinde öğrenciler artırılmış gerçekliğin birçok katkısı olduğunu düşünmektedirler. Özellikle artırılmış gerçeklik uygulamaları ile konuları daha iyi öğrendiklerini ve anladıklarını belirtmişlerdir. Tüm bu görüşler öğrencilerin akademik başarılarındaki olumlu artışın tespit edildiği bulgu ile paraleldir.

\section{Artırılmış gerçeklik uygulamaları ile hazırlanmış bir ortamda konuları öğrenmek isteseydiniz neler eklemek isterdiniz?}

Deney grubu öğrencilerinin artırımış gerçeklik uygulamalarının katkılarını tespit etmek amacıyla yöneltilen ikinci soru ve alınan yanıtlar Tablo 5'te belirtilmiş ve yorumlanmıştır.

Tablo 5. Tekrar artırılmış gerçeklik uygulamaları ile hazırlanmış bir ortamda konuları öğrenmek isteseydiniz neler eklemek isterdiniz?

\begin{tabular}{|c|c|c|c|}
\hline $\begin{array}{l}\text { E. Tekrar artırılmış gerçeklik uygulamaları ile hazırlanmış bir ortamda konuları öğrenmek } \\
\text { isteseydiniz neler eklemek isterdiniz? }\end{array}$ & $\mathrm{N}$ & $f$ & $\%$ \\
\hline Kullandığım telefonun daha sağlam ve daha hızlı olmasını isterdim & 32 & 24 & 73 \\
\hline Daha fazla etkinlik olmasını isterdim & 33 & 29 & 88 \\
\hline Uygulamanın daha hızlı olmasını isterdim & 33 & 25 & 76 \\
\hline Uygulamaları web cam aracılığı ile de bilgisayar başında denemek isterdim. & 33 & 18 & 54 \\
\hline Artırılmış gerçeklik uygulamaları ile daha çok çalışmak isterdim & 32 & 21 & 64 \\
\hline Uygulamalarda sorularında olmasını isterdim. & 33 & 19 & 57 \\
\hline Uygulamalarda daha çok etkileşimin olmasını isterdim & 33 & 25 & 75 \\
\hline
\end{tabular}

Öğrencilerin artırılmış gerçeklik uygulamaları ile tasarlanmış bir konuya yönelik görüşlerini tespit etmek amacıyla "Tekrar artırılmış gerçeklik uygulamaları ile hazırlanmış bir ortamda konuları öğrenmek isteseydiniz neler eklemek isterdiniz?" sorusu adı 
altında çeşitli alt sorulara yer verilmiş ve öğrencilerin cevapları alınmıştır. Öğrencilerin \%73’ü “Kullandığım telefonun daha sağlam ve daha hızı olmasını isterdim" yanıtını vermiştir. Öğrencilerin \%88'i "Daha fazla etkinlik olmasını isterdim" yanıtını vermiştir. Öğrencilerin \%76'sı “Uygulamanın daha hızlı olmasını isterdim” yanıtını vermiştir. Öğrencilerin \%54'ü “Uygulamaları web cam aracılı̆̆ı ile de bilgisayar başında denemek isterdim." yanıtını vermiştir. Öğrencilerin \%64'ü "Artırılmış gerçeklik uygulamaları ile daha çok çalışmak isterdim" yanıtını vermiştir. Öğrencilerin \%57'si “Uygulamalarda sorularında olmasını isterdim." yanıtını vermiştir. Öğrencilerin \%75’i “Uygulamalarda daha çok etkileşimin olmasını isterdim" yanıtını vermiştir. Öğrencilerin verdikleri yanıtlar analiz edildiğinde özellikle kullanılan donanımsal aygıtların daha üst düzey olması ve hazırlanan yazılımın daha hızlı olması gerektiğini belirtmişlerdir.

\section{Öğrencilerin uygulamaya yönelik eklemek istedikleri neler?}

Deney grubu öğrencilerinin uygulamalara yönelik eklemek istediklerini tespit etmek amacıyla yöneltilen altıncı soru ve alınan yanıtlar Tablo 6'da belirtilmiş ve yorumlanmıştır.

\section{Tablo 6. Uygulamaya yönelik eklemek istedikleriniz nelerdir?}

\begin{tabular}{|c|c|c|c|}
\hline F. Uygulamaya yönelik eklemek istedikleriniz nelerdir? & $\mathrm{N}$ & $f$ & $\%$ \\
\hline Artırılmış gerçeklik ile ilgili uygulama saatinin daha çok olmasını isterim & 33 & 18 & 54 \\
\hline Artırılmış gerçeklik ile ilgili uygulama etkinliklerinin daha çok olmasını isterim & 33 & 24 & 74 \\
\hline Telefonların veya tabletlerin daha iyi olmasını isterim & 33 & 27 & 82 \\
\hline Her dersi artırılmış gerçeklik uygulamaları ile işlemek isterdim. & 33 & 19 & 58 \\
\hline
\end{tabular}

Öğrencilerin uygulamalara yönelik eklemek istediklerini tespit etmek amacıyla "Uygulamaya yönelik eklemek istedikleriniz nelerdir?" sorusu adı altında çeşitli maddelere yer verilmiş ve öğrencilerin cevapları alınmıştır. Öğrencilerin \%54'ü “Artırımış gerçeklik ile ilgili uygulama saatinin daha çok olmasını isterim" yanıtını vermiştir. Öğrencilerin \%74'ü "Artırılmış gerçeklik ile ilgili uygulama etkinliklerinin daha çok olmasını isterim" yanıtını vermiştir. Öğrencilerin \%82'si "Telefonların veya tabletlerin daha iyi olmasını isterim" yanıtını vermiştir. Öğrencilerin \%58'i “Her dersi artırılmış gerçeklik uygulamaları ile işlemek isterdim." yanıtını vermişlerdir.

\section{SONUÇ VE ÖNERILER}

Artırılmış gerçeklik uygulamalarının gösterildiği deney grubunda öğrenim gören öğrencilerin büyük çoğunluğu derslerin daha zevkli ve eğlenceli olduğunu belirtmişlerdir. Bu yönüyle artırılmış gerçeklik uygulamaları ile öğretim sürecinin daha zevkli ve eğlenceli bir hale geldiği söylenebilir. Öğrenciler artırılmış gerçeklik uygulamaları ile konuları daha iyi öğrendiklerini belirtmiş̧lerdir. Bu da öğrencilerin akademik başarı düzeylerine olumlu yönde etki edebilir. Bu araştırmanın sonucuna paralel olarak Akçayır ve Akçayır (2017) artırılmış gerçeklik uygulamalarının öğrenmeyi daha eğlenceli bir hale getirdiğini ve öğrencilerin daha iyi anladıklarını belirtmektedir. Aynı şekilde Sırakaya ve Seferoğlu (2016) artırılmış gerçeklik teknolojisinin birçok faydasından bahsetmekte bu faydalar arasında öğrenmeyi daha eğlenceli hale getirdiğini belirtmektedir. Radu (2012) artırılmış gerçeklik uygulamalarının birçok olumlu ve olumsuz etkisinin olduğundan bahsetmekte ve bunlar arasında motivasyonu, işbirliğini artırma, daha kolay öğrenmeni gibi birçok özellikten bahsetmektedir. Rambli, Matcha ve Sulaiman (2013) bu çalışmaya paralel olarak artırılmış gerçeklik uygulamalarının öğrenme sürecinde katılımı artırdığı ve eğlenmeyi sağladığını belirtmektedir. Abdüsselam (2014) tarafından yapılan araştırmaya göre artırılmış gerçeklik ortamının öğrencilerin olayları daha iyi anlamalarına ve kavramalarına yardımcı olduğu, bu ortamın uygulamalarda daha gerçekçi bir ortam sunduğu, görselleştirdiği ve kavramları somutlaştırdığı sonucuna ulaşılmıştır. Başka bir araştırmada artırılmış gerçekliğin kullanıldığı sınıfta eğitimin daha eğlenceli olduğu sonucuna ulaşılmıştır (Bicen ve Bal, 2016). Yine başka bir araştırmada artırılmış gerçeklik teknolojisi ile öğrenme açısından gerçeklik hissinin oluştuğu, konuyu somutlaştırdığı, derse karşı ilgiyi artırdığı sonucuna varılmıştır (Küçük, Kapakin ve Göktaş, 2015).

Yazılım açısından çok az öğrenci uygulamaların yavaş çalışması ile ilgili sorunlar yaşadığını belirtmiştir ve bunun dışında öğrenciler artırılmış gerçeklik uygulamaları ile ilgili büyük bir güçlükle karşılaşmamışlardır. Yazılım açısından yaşanan hız sorunu bazı öğrencilerin telefonlarının daha eski olmasından kaynaklanabilir. İlgili alanyazı incelendiğinde teknolojik açıdan öğrencilerin daha önce karşılaşmadıkları bir teknoloji ile karşılaşmaları ve bunun üstesinden gelmede zorlanmaları (Wu, Lee, Chang ve Liang, 2013), artırılmış gerçeklik teknolojisinin kullanımını zor bulması (Saidin, Halim ve Yahaya, 2015 ) gibi birçok problem yer almaktadır. Bu uygulamada ise öğrenciler genel olarak uygulamayı bireysel kendi akıllı telefonları ile denemişlerdir ve büyük bir problemle karşılaşmamışlardır.

Öğrenciler hazırlanan uygulamalar ile fiziği daha iyi öğrendiklerini belirtmişlerdir. Öğrencilerin büyük bir kısmı fizik dersi optik ünitesi ile ilgili hazırlanan işaretleyici tabanlı artırılmış gerçeklik uygulamalarını eğlenceli, güzel ve eğitici olarak nitelendirmişlerdir. Marker tabanlı hazırlanan uygulamalar ile öğretim süreci ile başka dersler de daha eğlenceli, güzel ve eğitici uygulamalar geliştirilebilir. Öğrencilerin büyük bir kısmı artırılmış gerçeklik uygulamaları ile konuları çok daha iyi anladıklarını belirtmişlerdir. Öğrenciler uygulama kapsamında kullandıkları telefonların daha sağlam ve daha hızlı olması gerektiğini belirtmişlerdir. Ayrıca 
gösterilen etkimlikler dışında daha fazla etkinliğin olması gerektiği görüşündedirler. Bu sebeple birçok alanda birçok ders için farklı uygulamalar geliştirilebilir. Öğrenciler tarafından belirtilen diğer bir görüş uygulama ile ilgili yazılımın daha hızlı olması gerektiğidir.

Donanım açısından ise akıllı telefon ve tabletler dışında masaüstü bilgisayar ve web cam aracılığı ile de uygulamaların denenebileceği öğrenciler tarafından belirtilmiştir. Web Cam aracılığı ile uygulamaların gösterilmesi veya öğrencilerin uygulamaları yapabilmesi için uygun bir bilgisayar labaratuvarı bulmak zor olabilir. Fakat ileride özellikle artırılmış gerçeklik uygulamaları için özel ortamlar tasarlanabilir ve uygulamalar daha etkin bir biçimde gerçekleştirilebilir. Öğrencilerin artırılmış gerçeklik uygulamaları ile daha çok çalışmak istemesi, uygulamalarda daha çok etkileşimin olması ve uygulamalarda sorularında olması öğrencilerin önemli görüşleri arasında yer almaktadır. Bu bağlamda ileride geliştirilecek uygulamalar için bu hususlar dikkate alınabilir. Diğer derslerde de artırılmış gerçeklik uygulamalarının kullanılabileceğini öğrenciler belirtmişlerdir.

\section{Etik Kurul Onay Bilgileri}

2020 yılı itibari ile başvuru yapan araştırmacıların deneysel desenlenmiş makaleleri ile ilgili Etik Kurul Onay Belgesi'ni de sisteme yüklemeleri gerekmektedir. Makale yayın başvurusunda sisteme yüklenilen “Etik Kurul Onay Belgesi”ne ilişkin “kurum adı, tarih, sayı vb." bilgiler burada verilir.

\section{KAYNAKÇA}

Abdüsselam, S. M. (2014). Teachers' and students' views on using augmented reality environments in physics education: 11th Grade magnetism topic example. Pegem Journal of Education \& Instruction, 4(1), 59-74.

Akçayır, M. \& Akçayır, G. (2016). Advantages and challenges associated with augmented reality for education: A systematic review of the literature. Educational Research Review. 20, 1-11.

Akçayır, M. ve Akçayır, G. (2016). Üniversite öğrencilerinin yabancı dil eğitiminde artırılmış gerçeklik teknolojisi kullanımına yönelik görüşleri. Erzincan Üniversitesi Eğitim Fakültesi Dergisi, 18(2), 1169-1186.

Akkuş, i. \& Özhan, U. (2017). Matematik ve geometri eğitiminde artırılmış gerçeklik uygulamaları. Inönü Üniversitesi Eğitim Bilimleri Enstitüsü Dergisi, 4(8), 19-33.

Alkhamisi, O., A. Ve Monowar, M. M. (2013). Rise of augmented reality: current and future application areas. International Journal of Internet and Distributed Systems,1, 25-34.

Azuma, T. R. (1997). A survey of augmented reality. In Presence: Teleoperators and Virtual Environments 6, 355-385.

Bicen, H. \& Bal, E. (2016). Determination of student opinions in augmented reality. World Journal on Educational Technology: Current Issues. 8(3), 205-209.

Cai, S.,Chiang, K. F., Sun, Y., Lin, C. \& Lee, J. J. (2017). Applications of augmented reality-based natural interactive learning in magnetic field instruction. Interactive Learning Environments, 25(6), 778-791.

Cheng, K.H \& Tsai, C.C. (2013). Affordances of augmented reality in science learning: suggestions for future research. Journal of Science Education and Technology,22(4), 449-462.

Coimbra , T. M., Cardoso, T. \& Mateus, A. (2015). Augmented reality: An enhancer for higher education students in math's learning? Procedia Computer Science, 67, 332 - 339.

Dünser, A., Walker, L., Horner, H. \& Bentall, D. (2012). Creating interactive physics education books with augmented reality. Paper presented at the 24th Australian Computer-Human Interaction Conference, Melbourne, Victoria. Retrieved from https://www.researchgate.net/publication/262366547_Creating_interactive_physics_education_books_with_augmented _reality.

Fisk, P.(2017). Education 4.0 ... the future of learning will be dramatically different, in school and throughout life. Retrieved from https://www.thegeniusworks.com/2017/01/future-education-young-everyone-taught-together/.

Fleck, S. \& Simon, G. (2013). An augmented reality environment for astronomy learning in elementary grades: An exploratory study. Paper presented at 25ème conférence francophone sur l'Interaction HommeMachine, IHM'13, Nov 2013, Bordeaux, France. Retrieved from https://hal.inria.fr/hal-00870478v1/document.

Fleck, S., Hachet, M. Ve Bastien, C., J., M. (2015). Marker-based augmented reality: Instructional-design to improve children interactions with astronomical concepts. Paper presented at the 14th International Conference on Interaction Design and Children. Retrieved from https://www.researchgate.net/publication/276309758_Markerbased_augmented_reality_Instructional-design_to_improve_children_interactions_with_astronomical_concepts.

Gün, T. E. \& Atasoy, B. (2017). Artırılmış Gerçeklik Uygulamalarının İlköğretim Öğrencilerinin Uzamsal Yeteneklerine ve Akademik Başarılarına Etkisi. Journal of Education and Science, 42, 31-51.

Hsu, T-C. (2017). Learning English with Augmented Reality: Do learning styles matter? Computers \& Education, 106, $137-149$.

Ibanez, B. M., Serio, D. A., Villaran, D. \& Kloos, D. C. (2014). Experimenting with electromagnetism using augmented reality:Impact on flow student experience and educational effectiveness. Computers \& Education,71,1-13. 
İbili, E. (2013). Geometri dersi için artırılmış gerçeklik materyallerinin geliştirilmesi, uygulanması ve etkisinin değerlendirilmesi. (Doktora Tezi). Gazi Üniversitesi Eğitim Bilimleri Enstitüsü. Ankara.

İşman, A. (2001). Bilgisayar ve Eğitim. Sakarya Üniversitesi Eğitim Fakültesi Dergisi, 0(2), 1-34.

Kerawalla, L., Luckin, R., Seljeflot, S. \& Woolard, A. (2006). "Making it real": exploring the potential of augmented reality for teaching primary school science. Virtaul Reality, 10(3), 163-174.

Kırıkkaya, B. E.\& Şentürk, M. (2018). Güneş sistemi ve ötesi ünitesinde artırılmış gerçeklik teknolojisi kullanılmasının öğrenci akademik başarısına etkisi. Kastamonu Üniversitesi Kastamonu Eğitim Dergisi, 26(1), 181-189.

Krevelen, F.W.D ve Poelman, R. (2010). A survey of augmented reality technologies, applications and limitations. The International Journal of Virtual Reality, 2010, 9(2),1-20.

Küçük, S. (2015). Mobil artırılmış gerçeklikle anatomi öğreniminin tıp öğrencilerinin akademik başarıları ile bilişsel yüklerine etkisi ve öğrencilerin uygulamaya yönelik görüşleri. (Doktora Tezi). Atatürk Üniversitesi Eğitim Bilimleri Enstitüsü. Ankara.

Kuhn, J., Nussbaumer, A., Pırker, J., Karatzas, D., Pagani, A., Conlan, O., Memmel, M., Steiner, M.C., Gutl, C., Albert, D. \& Dengel, A. (2015). Advancing physics learning through traversing a multi-modal experimentation space. Paper presented at the 11th International Conference on Intelligent Environments, Prague.

Küçük, S., Kapakin, S. Ve Göktaş, Y. (2015). Tıp fakültesi öğrencilerinin mobil artırılmış gerçeklikle anatomi öğrenimine yönelik görüşleri. Yükseköğretim ve Bilim Dergisi, 5(3), 316-323.

Lopez, P. D. \& Contero, M. (2013). Delivering educational multimedia contents through an augmented reality application: a case study on its impact on knowledge acquisition and retention. The Turkish Online Journal of Educational Technology, 12(4), 19-28.

Nielsen, B. L., Brandt, H. \& Swensen, H. (2016). Augmented reality in science education-affordances for student learning.Nordic Studiesin Science Education,12(2), 157-174.

Özarslan,Y. (2013, Ocak). Öğrenme ve öğretmenin genişletilmiş gerçeklik ile zenginleştirilmesi: OptikAR uygulaması. Akademik Bilişim 2013 Konferansı'nda sunulmuş bildiri, Akdeniz Üniversitesi, Antalya. Erişim adresi: https://ab.org.tr/ab13/kitap/ozarslan_AB13.pdf.

Özerbaş, A. M. Ve Erdoğan, B.H. (2015). Dijital sınıf uygulamasına ilişkin öğrenci görüşleri. Ahi Evran Üniversitesi Kırşehir Eğitim Fakültesi Dergisi, 16(1), 357-369.

Öztemel, E. (2018). Eğitimde yeni yönelimlerin değerlendirilmesi ve eğitim 4.0. Journal of University Research,1(1), 25-30.

Radu, I. (2012). Why should my students use AR? A comparative review of the educational impacts of augmented-reality. Paper presented at the ISMAR 2012 - 11th IEEE International Symposium on Mixed and Augmented Reality 2012, Science and Technology Papers, Atlanta,GA.

Rambli, D. R. A., Matcha, W., \& Sulaiman, S. (2013). Fun learning with AR alphabet book for preschool children. Procedia Computer Science, 25, 211-219.

Serio, D. A., Ibanez, B. M. \& Kloos, D. C. (2013). Impact of an augmented reality system on students' motivation for a visual art course. Computers \& Education, 68, 586-596.

Şengören, S. K., \& Kavcar, R. T. N. (2006). Optik dersine yönelik tutum ölçeği geliştirilmesi. Pamukkale Üniversitesi Eğitim Fakültesi Dergisi, 20(20), 63-68.

Sırakaya, M. ve Seferoğlu, S. S. (2016). Öğrenme ortamlarında yeni bir araç. Bir eğitlence uygulaması olarak artırılmış gerçeklik. İşman, A., Odabaşı, F. Ve Akkoyunlu, B. (Ed). Eğitim teknolojileri okumaları (25. Bölüm, s. 417-438). TOJET ve Sakarya Üniversitesi, Adapazarı.

Siltanen, S. (2012). Theory and applications of marker-based augmented reality. Espoo, VTT Technical Research Centre of Finland.

Singhal, S., Bagga, S., Goyal, P. \& Saxena, V. (2012). Augmented chemistry: Interactive education system. International Journal of Computer Applications, 49(15), 1-5.

Swensen, H. (2016, November). Potentıal of augmented reality in sciences education. A literature review. Paper presented at the 9th International Conference of Education, Research and Innovation.

Techakosit, S. \& Nilsook, P. (2015). Using augmented reality for teaching physics. The sixth International e-Learning Conference,282-287.

.Torregrosa, F. J., Torralba, J., Jimenez, A. M., Garcia, S. \& Barcia, M. J. (2015). ARBOOK: Development and assessment of a tool based on augmented reality for anatomy. Journal of Science Education and Technology, 23(5), 119-124.

Yen, J-C,, Tsaib, C-H., Wua, M. (2013). Augmented reality in the higher education: Students' science concept learning and academic achievement in astronomy. Procedia - Social and Behavioral Sciences, 103, 165 - 173.

Yıldırım, A. ve Şimşek, H. (2005). Sosyal bilimlerde nitel araştırma yöntemleri. Ankara: Seçkin.

Wu, H.-K., Lee, S. W.-Y., Chang, H.-Y., \& Liang, J.-C. (2013). Current status, opportunities and challenges of augmented reality in education. Computers \& Education, 62, 41-49. 